\title{
EXPERIENCE WITH THE MANAGEMENT OF THROMBOEMBOLISM IN PATIENTS WITH SPINAL CORD INJURY: PART I. INCIDENCE, DIAGNOSIS AND ROLE OF SOME RISK FACTORS
}

\author{
By Arundhati Perkash, M.D., Ph.D., Ved Prakash, M.D. and Inder Perkash, M.D. \\ Spinal Cord Injury Center and Laboratory Service, \\ Veterans Administration Hospital, Palo Alto, California
}

Abstract. Fifty acute SCI patients are reviewed retrospectively for incidence of deep vein thrombosis and pulmonary embolism and the problems encountered in the diagnosis. The possible role of some risk factors in triggering thromboembolism and the consequent implications in anticoagulant therapy are discussed.

Key words: Acute spinal cord injury; Deep vein thrombosis; Pulmoary embolism; Anticoagulation.

\section{Introduction}

THE patients with acute spinal cord injury (SCI) are highly prone to the development of deep vein thrombosis (DVT) (Philipps, 1963; Watson, I968) often leading to fatal pulmonary embolism (Tribe, 1963; Hachen, 1974). The incidence of DVT in SCI patients during the first several weeks has varied from I4 per cent by clinical and radiological diagnosis (Philipps, I963), 6I per cent using impedance plethysmography and contrast venography (Todd et al., 1976), to Ioo per cent as determined by ${ }^{125}$ I fibrinogen uptake (Todd et al., 1976). Pulmonary embolism $(\mathrm{PE})$ is a major cause of death for a few weeks after acute SCI. The incidence of $\mathrm{PE}$ has been reported to be $\mathrm{I} 4$ per cent using clinical symptoms, X-ray and enzyme studies for diagnosis (Silver and Moulton, 1970), I5 per cent using lung scan (Naso, 1974) and 36 per cent as the cause of death at autopsy (Tribe, 1963). The diagnosis of pulmonary embolism is often difficult in normal persons (Robin, I977) and poses even additional problems in high level SCI patients.

At present, the therapy of DVT in SCI patients is based on the assumption that the pathogenesis of the deep vein thrombosis in SCI patients is similar to that occurring after major surgery (Sevitt and Gallagher, I96I). This includes the important factor of sluggish venous return of the paralysed limbs in the flaccid state (Wright et al., 1952). In general, the acute SCI patients are considered to be in a 'hypercoagulable state' (Naso, I975) but the period for which they remain susceptible to thromboembolism, and the trigger mechanisms, are uncertain.

This paper reports on: (I) the incidence of thromboembolism and the problems encountered in its diagnosis in acute spinal cord injury patients using: (a) impedance plethysmography and contrast venography for the diagnosis of deep vein thrombosis and (b) a combination of clinical symptoms, $\mathrm{PaO}_{2}$, lung scan and plasma protamine paracoagulation test for pulmonary embolism; (2) the possible role of some risk factors in the pathogenesis and prophylaxis of deep vein thrombosis and pulmonary embolism. The details of the anticoagulation therapy will be presented in a subsequent communication. 


\section{Methods and Materials}

Fifty patients with acute spinal cord injury admitted to the V.A. Hospital, Palo Alto, California, between July 1976 to November 1977, were included in the study. The interval between the time of injury and admission of spinal cord injury service varied from 4 to 90 days. All patients were male, aged i 9 to 62 years.

Spinal cord trauma was the cause of paralysis in 48 patients. In two patients, paralysis was due to transverse myelitis and Guillain-Barré Syndrome, respectively. Level of clinical lesion varied from $\mathrm{C}_{4}$ to $\mathrm{L}_{3}$. The segment distribution was: 27 cervical, 18 thoracic and five lumbar.

Care of patients included turning every two hours, use of TED hoses, physical therapy in the form of passive ranging and exercises, and respiratory therapy.

All patients were carefully screened for DVT by the following methods: thermia.

I. Physical examination for obvious swelling, pitting oedema and local hyper-

2. Thigh and calf circumference measurement taken at a fixed point $20 \mathrm{~cm}$ above and below the superior margin of the patella. These measurements were taken every day until the patient became ambulatory on wheelchair, or the muscle tone returned in the lower limb.

3. An electrical impedance plethysmographic study was performed on admission and then at weekly intervals on each patient, while they were confined to bed. Interpretation of the plethysmogram was done as described by Johnston et al. (1974).

Any patient with a change in the thigh and calf circumference of over $1.5 \mathrm{~cm}$, was evaluated further. Impedance plethysmogram was obtained immediately and, if needed, was followed by contrast venography.

In patients with clinical symptoms of pulmonary embolism, arterial blood gases on room air, a chest radiograph and lung scan were done whenever possible. Perfusion lung scan was done using ${ }^{99} \mathrm{~m}$ Tc-macroaggregated Albumin particle. Serial protamine dilution test was performed in selected patients by the method of Gurewich and Hutchinson (I97I).

Patients with DVT and/or pulmonary embolism were treated with heparin followed by coumadin. None of the patients were receiving aspirin at the time of development of thromboembolism.

\section{Results}

I. Incidence of Thromboembolism: The total incidence of thromboembolism was 18 per cent. One patient (Case no. I) developed PE without detectable DVT. Thus, the diagnosed incidence of DVT was I6 per cent (Table I).

I. Relative efficacy of methods in the diagnosis of DVT (Table I): Thirteen out of 50 patients showed abnormal leg measurements. In one patient who died of pulmonary embolism before therapy, the DVT was diagnosed on autopsy. Out of the remaining 12 patients, seven showed abnormal plethysmogram as well as abnormal contrast venography confirming DVT. Among five patients with normal IPG, abnormal calf measurements were considered to be due to heterotopic calcification in two patients (diagnosed on bone scan), haematoma thigh in two, and unequal muscle mass between the paralysed and unparalysed leg in one patient.

III. Pulmonary embolism: The diagnosis of PE was confirmed in four patients. Two were diagnosed at autopsy. One patient died soon after admission 
TABLE I

Observations on thromboembolism in 50 acute spinal cord injured patients

\begin{tabular}{lc}
\hline & $\begin{array}{c}\text { No. of } \\
\text { patients }\end{array}$ \\
\hline I. Patients with thromboembolism & $9(18 \%)$ \\
2. Patients in whom DVT was detected & $8(\mathrm{I} 6 \%)$ \\
3. Abnormal leg measurements & $\mathrm{I} 3$ \\
(a) Diagnosis at autopsy (Case no. 9) & $\mathrm{I}$ \\
(b) Abnormal impedance plethysmogram and positive contrast venography & 7 \\
(c) Abnormal measurements (but normal plethysmogram and normal & \\
venogram & 5 \\
(i) heterotopic calcification & 2 \\
(ii) haematoma & 2 \\
(iii) unequal muscle mass & $\mathrm{I}$ \\
4. Pulmonary embolism (confirmed) & $4(8 \%)$ \\
(a) Diagnosis at autopsy & 2 \\
(b) PE without detectable DVT & 2 \\
5. PE suspected (confirmatory tests could not be done) & 3 \\
6. Mortality due to DVT and PE (before treatment) & I \\
7. Mortality due to DVT and PE after anticoagulant therapy & 0 \\
\hline
\end{tabular}

without any diagnostic tests or therapy. The second patient had a long history of leg vein thrombosis, and had developed DVT 42 days post-injury. He was treated with coumadin for four months and developed fatal PE II days after stoppage of therapy. The PE in the other two patients was diagnosed by lung scan.

In three patients, $\mathrm{PE}$ was suspected on clinical grounds, but it was not possible to confirm it either by lung scan (the lung scan could not be carried out in two patients because of acute cervical injury and in one patient it was negative), or by $\mathrm{PaO}_{2}$ (the values were lower than $80 \mathrm{~mm} \mathrm{Hg}$ prior to suspected $\mathrm{PE}$ ). The first patient (Case no. 2) suffered from chronic obstructive pulmonary disease in addition to being tetraplegic. He developed DVT in the right leg followed by deterioration of respiratory symptoms. The $\mathrm{PaO}_{2}$ before and during suspected episode of PE ranged from 43 to $75 \mathrm{~mm} \mathrm{Hg}$. Serial dilution protamine sulphate test was positive in I in Io dilution. Because of the established DVT, he was considered a potential candidate for PE and anticoagulated for a prolonged period.

The second patient (Case no. 3) was admitted with a history of shortness of breath on the airplane during his transfer to this hospital. On admission he had DVT in right leg and was suspected to have had PE during transportation. His initial $\mathrm{PaO}_{2}$ was $55 \mathrm{~mm} \mathrm{Hg}$ which improved to $86 \mathrm{~mm} \mathrm{Hg}$ after intratracheal suction. The lung scan was not done because of cervical traction. The SDPS was positive in I in Io dilution, indicating recent intravascular clotting. He was treated with heparin, requiring very large doses. His chest X-ray became clear after 4 days of heparin therapy. Heparin was followed by coumadin therapy for four months. It was then discontinued because the patient was ambulating in a wheelchair and he wished to travel. While on visit to another city, he developed a second episode of PE, confirmed by lung scan, but without clinical evidence of DVT.

The third patient (Case no. 4) developed difficulty in breathing and rhonchi in both lungs 17 days after the diagnosis of extensive DVT in right leg and thigh, for 
THROMBOEMBOLISM：I

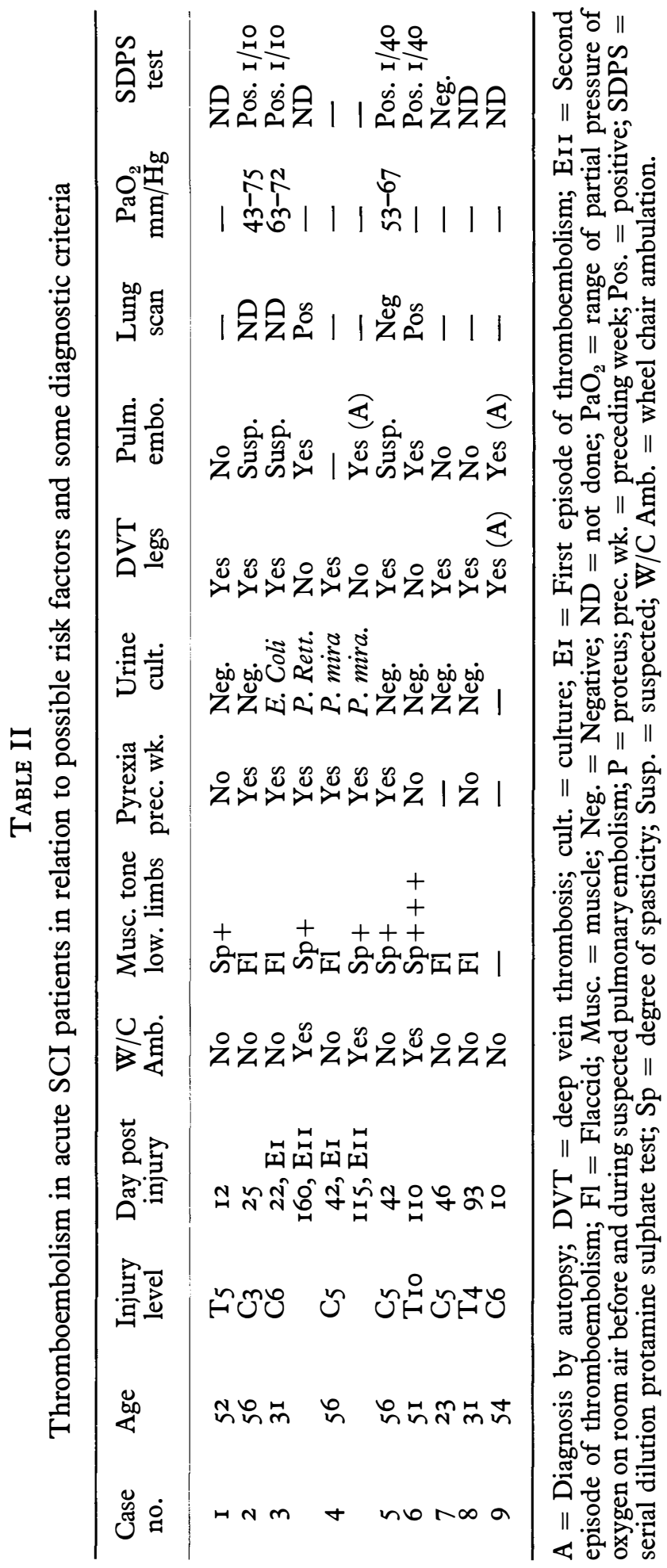


which he had been treated with heparin and coumadin. PE was suspected, but lung scan was negative and his $\mathrm{PaO}_{2}$ values had been low $(53-67 \mathrm{~mm} \mathrm{Hg}$ ) even prior to suspected PE. The SDPS was positive in I in 40 dilution. Because of a recent previous episode of DVT, he was treated with heparin for suspected PE. The respiratory symptoms subsided on heparin therapy alone.

In three patients (Case nos. 3, 4, and 6), PE occurred without any clinical evidence of DVT in legs at the time. In two patients (Case nos. 3 and 4) PE was the second episode of thromboembolism occurring II 5 and I60 days post-injury, respectively; occurring at a time when coumadin therapy for the first thrombotic episode had just been discontinued.

IV. Incidence of DVT on admission and after hospitalisation: Three patients already had DVT at the time of admission (IO, I2, and 22 days post-injury) while five developed it during their stay in the hospital. One patient developed DVT and PE II 5 days post-injury while residing in a nursing home.

V. DVT in relation to age and level of injury (Table II): Five patients were below 35 years of age, while four were between 50 and 60 years of age. Six patients were quadriplegic and three paraplegic.

VI. DVT in relation to period after injury: The period between the injury and diagnosis of thromboembolism ranged from Io to I60 days. In ascending order the period for the first diagnosed episode was I0, I2, 22, 25, 42, 46, 63, 93, and I Io days respectively. Two patients (Case nos. 3 and 4 ) had recurrent thromboembolism, first episode occurring 22 and 4.2 days, and second episode 160 and I I 5 days after injury respectively. Thus, out of I I episodes of thromboembolism, three occurred beyond twelve weeks post-injury.

VII. DVT in relation to the tone of muscles in the lower extremities: At the time of development of DVT, the muscles were flaccid in four patients, mildly spastic in one and markedly spastic in one. In two patients (Cases nos. 3 and 4), the first episode of DVT was diagnosed and treated during flaccid stage and during the phase of muscle tone recovery while the lower limbs showed mild spasticity, pulmonary embolism occurred without detectable DVT in the legs.

VIII. DVT in relation to the body weight and build: Only two out of nine patients were moderately overweight. The body weight and height $(\mathrm{kg} / \mathrm{feet}$ and inches) relationships in nine patients was 55/5 $10^{\prime \prime}, 65 / 6^{\prime} \mathrm{I}^{\prime \prime}, 68 \cdot 6 / 6^{\prime} 2^{\prime \prime}, 70 / 6^{\prime} \mathrm{I}^{\prime \prime}$, $71 / 5^{\prime} 7^{\prime \prime}, 76 / 5^{\prime}$ I I", 82/6', 105/6' 2", and I I2/6' 4", respectively.

IX. DVT in relation to surgical procedures and other associated injuries: In the group of nine patients with DVT, only one patient underwent surgery within 4 weeks prior to diagnosis of DVT. Three patients had surgery before the above mentioned period and five patients had no surgery at all. In the 4I patients who did not develop DVT, surgery was performed in 23 ( 56 per cent) patients. The operations included laminectomy, insertion of Harrington rods, posterior fusion, partial gastrectomy, and aortic bypass.

$\mathrm{X}$. DVT in relation to infection in the week preceding its diagnosis: Five out of nine patients with DVT had mild to moderate continuous or intermittent pyrexia. Urine culture was positive in two patients. Four out of five patients with pyrexia were treated with antibacterial agents. Urine cultures were negative in all patients on the day of diagnosis of DVT. Blood cultures were negative in all the patients and there was no significant leucocytosis during the period specified above.

\section{Discussion}

The incidence of DVT in this consecutive series of 50 patients using impedance plethysmography and contrast venography is I6 per cent. This is similar 
to the incidence of $\mathrm{I} 4$ to $2 \mathrm{I}$ per cent as diagnosed clinically by Walsh (I965), Watson (I968), Silver and Moulton (1970), Hachen (1974), and I4 per cent by clinical and radiological diagnosis (Philipps, 1963). This is much lower than that of Todd et al. (1976) who have reported an incidence of 6I per cent using impedance plethysmography and contrast venography. Whether this difference is due to the differences in patient sample or patient care is not clear. The level of injury in the two series is not significantly different ( 54 per cent quadriplegics in this series as against 60 per cent in Todd's series). Since Watson (I968) has reported a much higher incidence of DVT in the first $2 \mathrm{I}$ days after SCI, this difference could be accounted for if there was a preponderance of patients in the early phase in Todd's series; but, a breakdown of the period between injury and occurrence of DVT is not available for comparison from Todd's data.

The meticulous and regular measurement of the calf and thigh serves as a simple and inexpensive screening method for DVT. The greatest virtue of the impedance plethysmography is its ready availability and non-invasive technique. However, using IPG technical false positives can occur with certain positions of the leg such as an external tourniquet effect due to the electrodes, improper positioning of the thigh cuff, and the patient's clothing. The false positive IPG recordings can be avoided by repeating a positive recording after repositioning of the leg. Confirmation by venography, if available, is helpful in determining the exact site, extent and nature of thrombosis.

Among the factors that are considered as high risk for the development of DVT, our observations as well as previous surveys (Watson, I968; Todd et al., 1976) found no striking correlation between DVT and age, level of injury, body weight or preceding surgery. Absence of any relationship with surgery could be due to pre-existing paralysis and stasis in the lower limbs of acutely paralysed patients, thus masking the effects of surgery.

One of the factors that can trigger intravascular coagulation or thrombosis is the presence of endotoxins in the blood (McKay and Shapiro, I958). Since the rate of urinary tract infections is high in SCI patients, and they are subjected to frequent catheterisations, the bacteraemia resulting from such manipulations in patients with bladder infections, or even those with sterile urine (Sullivan et al., 1972) but contaminated urethra may trigger intravascular clotting in these already hypercoagulable patients. In patients with urinary tract infection, the deep pelvic veins would be specially vulnerable to thrombogenic effects of gram negative bacteria entering the venous circulation from the urinary bladder. In this series, four out of nine patients with thromboembolism had been treated with antibiotics for moderate pyrexia preceding the diagnosis of DVT. The urine cultures were positive in two and negative in the other two patients while blood cultures were negative in all the four patients. In those patients who have clinical manifestations of infection, such as fever, tachycardia, and leucocytosis, but negative blood or urine cultures, ' $L$ '-forms of bacteria have been implicated as the causative agent leading to the development of thromboembolism (Altemeier et al., 1969; Brogam, 1977). This sample of patients is small for any conclusions to be drawn, but if infection can or does play a role in triggering DVT, especially in pelvic veins, it would be logical to treat these patients with anticoagulants along with antibiotics.

In general, the return of tone in lower limbs is taken as an indication of improved venous circulation and decreased risk of DVT so that onset of spasticity is considered as one of the guidelines for discontinuation of anticoagulant therapy. The development of DVT in three of our patients with mild and one patient with 
marked spasticity, indicates that spastic limbs, especially those with mild degree of spasticity, are not immune to the development of DVT. Two of these patients (Case nos. 3 and 4) developed PE without detectable DVT on II 5 and I60 days post-injury respectively. Both had a previous episode of DVT and were treated with coumadin which was then discontinued. At the time of onset of PE, the lower limbs were already spastic in both the patients, and urine cultures were positive. Pulmonary emboli in these patients could have originated either from deep pelvic veins, possibly triggered by infection, or from legs which had mild spasticity. The venous circulation in such limbs may not be vigorous enough to prevent thrombosis but the contraction of even mildly spastic muscle may be sufficient to squeeze and dislodge an existing small thrombus before it is large enough to manifest locally. In such a situation, patients with mild spasticity may be even more vulnerable to pulmonary embolism and should continue to receive prophylactic anticoagulation until the spasticity has progressed and stabilised to a marked degree.

Dislodgement of thrombi with consequent sudden PE has been described during passive exercises (Shull and Rose, I966; Guttmann, 1973). We have, for this reason, withheld both passive and active exercises during the first 72 hours in patients after the diagnosis of deep vein thrombosis was made and only a gentle single range of motion of all the joints was allowed during the first week to prevent contractures. Activity was gradually increased when the patients were adequately anticoagulated and there was no evidence of progressive active thrombosis.

The high incidence of DVT in SCI patients warrants more aggressive prophylaxis. The prophylaxis in SCI patients has been attempted by oral anticoagulants (Silver, 1974) as well as low dose heparin (Casas et al., 1976), or a combination of both (Hachen, I974), with significant reduction in the incidence of thromboembolism. An unsettled point remains the period for which prophylaxis should be maintained and the criterion for the discontinuation of anticoagulation. Should anticoagulation cover only the high-risk period of 4 weeks after injury as recommended for post-operative patients (Adar and Salzman, 1975), or 12 weeks following injury, this being the period when majority of the patients develop thromboembolism, or, simply until wheelchair activity is resumed (Hachen, 1974; Casas, 1976)? It is apparent from our review that although the majority of the acute SCI patients develop thromboembolism within 12 weeks of injury, some continue to be susceptible over an extended period. In the series published by Silver (1974) 3 per cent of the patients developed DVT after the oral anticoagulants were arbitrarily discontinued at 12 weeks post-injury for bladder surgery, and he wondered if it was too short a time to stop the prophylactic treatment. In our series two patients developed the first episode of DVT beyond twelve weeks. In two patients a second episode of thromboembolism occurred at II 5 and I60 days post-injury respectively, after Coumadin therapy for the previous episode was discontinued. At present there is no modality available to screen out the patient with extended hypercoagulability, and, it is obvious that a fixed regime of arbitrary period of prophylactic anticoagulation may not cover the risk factors in all patients effectively. The prophylactic anticoagulation, therefore, has to be individualised by considering a number of factors which include the period after injury, degree of spasticity in lower limbs, ambulation, presence of infection, previous episodes of thromboembolism, and any evidence of recent intravascular coagulation.

The diagnosis of pulmonary embolism using currently accepted criteria based on clinical symptoms, hypoxaemia and perfusion lung scan poses several problems in acute SCI patients: (I) Clinically, there may be masking of mild symptoms such 
as chest pain, cough and haemoptysis (Silver and Moulton, 1970). (2) Pulmonary embolism may occur without any clinical evidence of DVT. The incidence of PE without clinical evidence of DVT in SCI patients has been reported as high as 50 per cent (Watson, I968; Naso, 1974), and occurred in one third of our patients. The DVT when present favours the diagnosis in a case of suspected PE. The diagnosis of mild pulmonary embolism in the absence of clinical DVT can be extremely difficult. In this situation, the serial dilution protamine sulphate test, if positive, lends strong support to diagnosis (Gurewich and Hutchinson, I97I). It is a non-specific test which detects the presence of fibrin monomer arising from a recent intravascular clotting including DVT in legs or pelvis and pulmonary embolism. Since fibrin monomers have a short half-life, the test is positive only for 48-72 hours after the fresh clotting episode. (3) Even in the absence of PE, the tetraplegic patients tend to have a low $\mathrm{PaO}_{2}$ due to paralysis of the respiratory muscles and complicating pneumonia. In general, $\mathrm{PaO}_{2}$ of $80 \mathrm{~mm} \mathrm{Hg}$ or less is accepted for the diagnosis of $\mathrm{PE}$, but many acute tetraplegics may run a $\mathrm{PaO}_{2}$ value of $70 \mathrm{~mm} \mathrm{Hg}$ or lower (Bergofsky, 1974) before the onset of PE, rendering this criteria ineffective for diagnosis. One of our patients suffered from chronic obstructive disease in addition to being tetraplegic, and his $\mathrm{PaO}_{2}$ fluctuated between 42 to $85 \mathrm{~mm} \mathrm{Hg}$ before and during suspected PE. (4) The lung scan may not be feasible sometimes due to serious neck and chest injuries. These problems arose in two of our patients suspected to have PE. Although the lung scan could not be done, they were treated for suspected PE with anticoagulants in view of current DVT in one patient and a previous episode of DVT in the other. In one patient in the present series, PE was suspected but lung scan was negative. Nevertheless, his respiratory symptoms subsided on heparin therapy alone. The lung scan also may not be easily available at odd hours. In every suspected case of PE where the specific diagnostic criteria can not meet non-specific tests such as X-ray, serial dilution protamine test, and lactic dehydrogenase estimation (Szucs et al., I97I) could be very helpful. If more than one of these tests support the clinical diagnosis, the patients should be treated with anticoagulants in view of their potential for developing fatal thromboembolic complications.

\section{SUMMARY}

A retrospective review of 50 acute spinal cord injury patients revealed an incidence of 16 per cent for deep vein thrombosis and 8 per cent for pulmonary embolism. Age, level of injury, body weight and preceding surgery had no striking correlation with thromboembolism. The period of susceptibility to thromboembolism after injury extended over a period ranging from Io to I60 days, about one fourth of the episodes occurring after 12 weeks of injury. The bacteraemia resulting from frequent catheter manipulations, especially of the infected urinary bladder, may possibly trigger deep vein thrombosis. Acute SCI patients may be more vulnerable to pulmonary embolism at the time of return of spasticity in lower limbs while it is still mild in degree. The diagnosis of pulmonary embolism in high level acute SCI patients presents difficulties due to masking of symptoms, initially low $\mathrm{PaO}_{2}$, silent deep vein thrombosis and unfeasibility of performing lung scan due to lung and chest injuries. Chest X-ray, serial dilution protamine sulphate test and lactic dehydrogenase estimation can be of help in making the diagnosis in such patients. The implications of these findings in anticoagulant treatment are discussed. 


\section{RÉSUMÉ}

Une enquête rétrospective concernant 50 malades atteints de lésion médullaire révèle une incidence de $16 \%$ de thrombose veineuse profonde et de $8 \%$ d'embolie pulmonaire. Aucune corrélation nette entre thromboembolie et âge, niveau lésionnel, poids, antécédents chirurgicaux n'a été constatée. La période de risque thromboembolique va de Io à I60 jours, un quart des épisodes survenant après I 2 semaines. La bactériemie liée aux chatétérismes, spécialement en cas d'infection vésicale, peut déclencher une thrombose veineuse profonde. Les malades avec lésion médullaire peuvent être plus vulnérables aux embolies pulmonaires lors du retour de la spasticité dans les membres inférieurs, même encore très modérée. Le diagnostic d'embolie pulmonaire est difficile pour les lésions médullaires aigües hautes, du fait des symptomes masqués, de l'abaissement de la $\mathrm{PaO}_{2}$, des thromboses veineuses profondes silencieuses et de l'impossibilité de réaliser un scanner pulmonaire en raison des lésions thoraco-pulmonaires. Chez de tels patients, peuvent aider au diagnostic: la radiographie thoracique, la courbe de dilution du sulfate de protamine, le dosage de la lacto-déhydrogénase. Les implications de ces données pour la conduite du traitement anticoagulant sont discutées.

\section{ZUSAMMENFASSUNG}

Ein Rückblick auf 50 Patienten mit akuten Verletzungen des Rückenmarks zeigt, dass I6\% Thrombose der tiefen Venen und $8 \%$ Lungenembolie erlitten. Das Alter, der Höhenquerschnitt der Verletzung, das Körpergewicht und vorhergehende Operation hatte keinen besonderen Einfluss auf die Thromboembolie. Der Zeitraum nach der Verletzung in dem Thromboembolische Komplikationen entstanden, erstreckte sich von Io bis I60 Tagen, ungefähr $\frac{1}{4}$ dieser Episoden entwickelte sich I2 Wochen nach der Verletzung. Die Blutvergiftung, verursacht durch die häufige Benützung von Kathetern, besonders in der infizierten Harblase könnte möglicherweise die tiefe Venenthrombose verursachen. Patienten mit akuter Rückenmarksverletzung fallen öfter einer Lungenembolie zum Opfer, besonders zur Zeit wenn die Spastizität der unteren Gliedmassen zurückkehrt aber noch mild ist. Die Diagnose der Lungenembolie in Patienten mit hochsitzenden akuten Rückenmarksverletzungen verursacht viele Schwierigkeiten, weil oft die Symptome maskiert sind, weil im Anfang der $\mathrm{PaO}_{2}$ niedrig ist, weil die tiefe Venenthrombose oft symptomlos ist und weil es nicht praktisch ist eine Lungenübersicht (scan) zu machen, da Lungen-und Thoraxverletzungen vorhanden sind. Röntgenaufnahme des Brustkorbs, Serienuntersuchung von Protamine Sulfate Verdünnungen und Bestimmung der Lactic Dehydrogenase kann bei solchen Patienten in der Diagnose helfen. Die Benützung von Antikoagulationstherapy in solchen Patienten wird diskutiert.

\section{REFERENCES}

AdAR, R. \& SALzMAN, E. W. (I975). Treatment of thrombosis of veins of the lower extremities. New Eng. F. Med., 292, 348.

Altemeier, W. A., Hill, E. O. \& Fullen, W. D. (I969). Acute and recurrent thromboembolic disease: a new concept in etiology. Ann. Surg., 170, 547.

BERGOFSKY, E. H. (I964). Mechanism for respiratory insufficiency after cervical cord injury. Ann. Intern. Med., 61, 435.

BRogam, O. (I977). The role of bacterial $\mathrm{L}$ form in urinary tract infections. Br. F. Urol., 49, 43.

Casas, E. R., Sanchez, M. P., Arias, C. R. \& Masip, J. P. (1976). Prophylaxis of venous thrombosis and pulmonary embolism in patients with acute traumatic spinal cord lesions. Paraplegia, 14, I78.

GuREWICH, V. \& HUTCHINSON, E. (I97I). Detection of intravascular coagulation by a serial dilution protamine sulfate test. Ann. Intern. Med., 75, 895.

Guttmann, L. (1973). Spinal Cord Injuries, Ist edn. Blackwell Scientific Publications, Oxford, p. I79.

HACHEN, H. J. (1974). Anticoagulant therapy in patients with spinal cord injury. Paraplegia, 13, 176.

Johnston, K. W., KaKKaR, V. V. \& SpindleR, J. J. (1974). A simple method for detecting deep vein thrombosis: an improved electrical impedance technique. Am. F. Surg., 127, 349. 
MCKAY, D. G. \& Shapiro, S. A. (1958). Alterations in blood coagulation system induced by bacterial endotoxin I in vivo (Generalized Schwartzman reaction). f. Exp. Med., I07, 353.

Naso, F. (1974). Pulmonary embolism in acute spinal cord injury. Arch. Phy. Med. Rehabil., 55, 275.

PhILIPPS, R. S. (I963). Incidence of deep venous thrombosis in paraplegia. Paraplegia, I, II6.

Robin, E. D. (1977). Overdiagnosis and overtreatment of pulmonary embolism. Ann. Intern. Med., 87, 775 .

SEAMAN, A. J. (1970). Recognition of intravascular clotting; plasma protamine paracoagulation test. Arch. Intern. Med:, I25, I0I6.

SevitT, S. \& Gallagher, N. G. (I96I). Prevention of venous thrombosis and pulmonary embolism in injured patients. Lancet, 2, 98I.

Shull, J. R. \& Rose, D. L. (I966). Pulmonary embolism in patients with spinal cord injuries. Arch. Phys. Med. Rehabil., 47, 444.

SILVER, J. R. (I974). The prophylactic use of anticoagulant therapy in the prevention of pulmonary emboli in one hundred consecutive spinal injury patients. Paraplegia, 12, I 88.

Silver, J. R. \& Moulton, A. (1970). Prophylactic anticoagulant therapy against pulmonary emboli in acute paraplegia. $B r$. Med. $\mathcal{F} ., 2,338$.

Sullivan, N. M., Sutter, V. L., Carter, N. T., Attebery, H. R. \& Finegold, S. M. (1972). Bacteremia after genitourinary tract manipulations: Bacteriological aspects and evaluation of various blood culture systems. Appl. Microbiol., 23, I IOI.

Szucs, M. M., Brooks, H. L., Grossman, W., Banas, J. S., Meister, S. G., Dexter, L. \& DALEN, J. E. (I97I). Diagnostic sensitivity of laboratory findings in acute pulmonary embolism. Ann. Intern. Med., 74, I6I.

Todd, J. W., Frisbie, J. H., Rossier, A. B., Adams, D. F., Als, A. V., Armenia, R. J., Sasahara, A. A. \& Tow, D. E. (1976). Deep venous thrombosis in acute spinal cord injury: a comparison of ${ }^{125}$ I fibrinogen leg scanning, impedance plethysmography and venography. Paraplegia, I4, 50.

Tribe, C. R. (I963). Causes of death in early and late stages of Paraplegia. Paraplegia, I, I9.

Walsh, J. J. \& Tribe, C. R. (1965). Phlebo-thrombosis and pulmonary embolism in paraplegia. Paraplegia, 3, 209.

Warlow, C., Ogston, D. \& Douglas, A. S. (1972). Venous thrombosis following strokes. Lancet, I, 1305 .

Watson, N. (I968). Venous thrombosis and pulmonary embolism in spinal cord injury. Int. F. Paraplegia, I, I I3.

Watson, N. (1974). Anticoagulant therapy in the treatment of venous thrombosis and polmonary embolism in acute spinal injury. Paraplegia, 12, 197.

Wright, H. P. \& OsBorn, S. B. (I952). Venous velocity in bed ridden medical patient. Lancet, 2, 699. 